\title{
STUDENTS' ATTITUDE AND ACCEPTANCE OF MATH STUDIES
}

\section{Sead Rešić}

\section{Admira Ahmetbegović}

Alma Škrobić

Department of Mathematics, Faculty of Sciences, University of Tuzla

Elementary school "Solina", Tuzla

Received: 16.05 .2012
Accepted: 12.07 .2012

Received: 16.05 .2012
Accepted: 12.07 .2012

\author{
Elementary school "Solina", Tuzla
}

Original scientific paper

\begin{abstract}
The aim of this paper is to ascertain the type of relation elementary school students have toward mathematics classes. Through employing technical and scientific methods, a basis was constructed which can provide answers to numerous questions related to math classes, relation of students towards the subject matter, as well as to results being achieved in the subject mathematics during elementary education. The fact is that elementary school students exhibit difficulties in accepting the subject and achieve lower results in mathematics in comparison to other school subjects. Likewise, it is a fact that students upon gradating elementary school opt for high schools which have less mathematics in their curricula, and this state of affair continues when choosing higher education area. In the first theoretical part, certain fundamental concepts regarding this research topic have been clarified. The second part relates to the methodology of research of the above-mentioned problem. In the third part an analysis and interpretation of the results of conducted research has been provided.
\end{abstract}

Key words: teaching process, teacher, professor, curriculum, mark, mathematics

\section{INTRODUCTION}

We have been listening to the same story for years, about senior grade students who achieve lower results in mathematics. Teachers usually complain about students who do not want to study and about curricula which are too voluminous and too difficult. They do not complain about themselves or their work. There are various reasons for this problem, namely too detailed and complex curricula, inadequately formed students' books etc. In this paper, we have attempted, based on available literature and a small-scale research, to shed some light on this problem.

\section{${ }^{1}$ Correspodence to:}

Sead Rešić, Department of Mathematics, Faculty of Science, University of Tuzla

Šabana Zahirović 10, Tuzla, B\&H

Phone: +38761101230 
The current situation is characterized by a multitude of negative marks and a great number of students seeking additional help and individual instructions for this school subject. Numerous students graduate without grasping even the basic mathematical skills. For society, the greatest problem is that many children with considerable capabilities, when deciding on high school or university education opt against curricula where mathematics is represented.

Possible reasons for such a negative attitude towards mathematics are fear that stems from distrust in one's own abilities to understand numbers, some are so afraid of making a mistake, of seeming ignorant or appearing stupid that they do not even want to think about math; then there is lack of exercise, using operations learned by heart, without understanding their meaning, which leads to feelings of senselessness and powerlessness, not understanding more complex operations due to not knowing the basic ones, misuse of the task procedure. However, the assumption is that the majority of students spend least time studying math. Since it can not be learned by heart, time dedicated to studying mathematics comes down to doing homework. Teachers in our country have a very interesting and far-fetched task ahead of them - to improve mathematics teaching process, which is at first glance 'elitist', 'obnoxious', 'brain-wrecking' and 'sterile' discipline, and steer it toward a desirable activity in everybody's education, in accordance to ever growing importance of mathematics in the world and the significance it should have in our country. We are hoping that this research will be of use, if not for wider community, then at least for us teachers (Legović, 2004).

\section{THEORETICAL CONSIDERATIONS OF THE PROBLEM}

\section{Overview of earlier research}

During the past century, the existence of specific difficulties in learning mathematics has been known of. Still, this issue has been investigated and recorded in scientific literature very poorly. There are but a few books in the world that tackle this problem. One of those books is named 'Math Without Tears - How to Help a Child With Difficulties in Learning Mathematics', written according to the work of professor Mahesh Sharma, provost and executive vice president of Cambridge College and director of world-renowned Center for learning and teaching mathematics. Professor Sharma is today the most eminent expert I the world for therapy of specific difficulties in learning mathematics in children and for teaching mathematics in schools. This book is a clear, all-encompassing and unique resource of practical information for professionals (psychologists, pedagogues and defectologists), teachers, professors, rehabilitation experts and parents of children with difficulties in studying mathematics. In a manner accessible to everybody, in a simple language, he explores in detail matters of recognizing, diagnosing, ameliorating and removing specific difficulties in studying mathematics, such as dyscalculia, anarithmetia, mathophobia etc. He offers a detailed, vividly illustrated, description of methods for efficient assistance and teaching and an elaboration on extraordinary didactic materials (Posokhova, 2009).

\section{Definition and significance of the research problem}

The problem which at the core of this research comprises of examining mathematics teaching process in higher elementary school grades, with the aim of providing guidelines and suggestions as to make it more accepted and less burdening for the student, and to explore relations and attitudes of students towards mathematics classes. The goal is to attempt to reveal whether curricula are too voluminous and too difficult, whether the subject itself is the reason for students' absence from classes, what are the teachers' demands, parents' ambitions etc. Fear of mathematics has for a long time been a pedagogical and social problem which results in negative pedagogical and educational consequences, which are manifested in a wider social community. That is why this research has theoretical, practical and social significance. 
Theoretical significance lies in the fact that researching pedagogical and educational consequences, in this case difficulties while mastering mathematics subject matter, should shed light and contribute, in modest proportions, to resolve the causes of difficulties and their influence on the occurrence of negative pedagogical-educational consequences and explore possibilities of their resolution. Studying mathematics and students' advancement in that direction depends on may various factors. Teacher, as one of the participants in the process, has an effect not only on achieving certain results in learning and working, but also on encouraging and developing numerous abilities and patterns of behavior. On the mathematics teacher's personality greatly depend qualitative and quantitative aspects of learning, interest and classroom climate, pedagogic and educational procedures, methods and results of management. Amiable learning climate and establishing positive social relationships are tightly interdependent and depend on the teacher's ability to understand students' problems and aspirations, and to balance their behavior. However, climate for learning mathematics depends also on the relationships between students themselves, and partly on the general atmosphere in the school as a whole. Practical significance of this research includes that which is of immediate importance to schools and teachers who will, based on the results of the research, and through their work, be able to contribute to unburdening students and better acceptance of mathematics subject matter. A great number of students begin to hate math during elementary school education, instead of growing to like it. Responsibility for this does not fall only on math teachers. The problem has deeper roots and it is not solely their responsibility. Firstly, it is a widely known fact that majority of students do not like mathematics as a school subject. It is interesting, although very sad, that more teachers are proud of that fact than there are those who think it is an embarrassment and problem which should be urgently dealt with. The depth of this problem can be seen throughout history of learning mathematics, where renowned schools and universities competed (unfortunately, this happens today as well) who will fail more students, and not which school will produce more good mathematicians, among which there would be excellent ones, too. The less students completed their studies, the more 'serious' the school was considered. The practical significance of this paper is also shown by the attempt to provide answers to questions, such as, why certain healthy and well-developed children experience difficulties in learning mathematics, how specific difficulties in studying affect mastering mathematics, how to recognize and help children with specific difficulties in learning math, why some gifted children have low accomplishments at school, how to help a child to study mathematics successfully and easily, what to do when a child is afraid of math, etc. Position of interest of young people in mathematics is on an unenviable level in our country, despite significant efforts invested in teaching mathematics. This is why the question we tackle here demand immediate action and a new impulse in mathematics teaching process (Legović, 2004).

\section{AIM, TASKS AND METHODOLOGY OF RE- SEARCH}

Starting from the stated above-mentioned problem, the aim of this paper is to research, critically analyze, ascertain and interpret students' relation towards mathematics classes and difficulties they encounter while mastering mathematics subject matter, as well as the kind of interest and willingness to study the mathematics curricula. In relation to the defined problem and set aim, there are numerous tasks laid for this research, in order to determine the relation and attitudes of students towards studying mathematics. The determined aim has been made concrete through the following tasks:

Determine whether mathematics curricula in elementary schools are too voluminous and too difficult;

Determine whether mathematics as school subject is the reason for students' absence from classes; Determine in what measure the teacher's manner of interpreting the subject matter is interesting and motivating;

Determine the students' attitude towards students' books; 
Determine the students' attitude towards their own mathematical knowledge and their opinion whether mathematics can be helpful in everyday life;

Determine the number of students who grade positively mathematics classes, and how many of them do not accept it.

Considering the aim of this research and theoretical knowledge, as well as previous research data, including our own present and past experiences, it is assumed that students reach lower achievement levels in mathematics in relation to other school subjects and exhibit fear from the subject. In this research, the set presupposition is that relation towards a school subject significantly depends on student's capabilities and interests. Nevertheless, the problem issue is also how much the student's interest or motivation to study a particular subject matter, in this case mathematics, relates to the methods and techniques of classwork, student's relation towards the teacher, the students' book and curriculum, as well as understanding the facts that make this school subject important for his/her life and how he/she can put it to use. Stemming from the main hypothesis, several subhypotheses have been set for this research:

It is assumed that mathematics curricula for elementary schools are too voluminous and too difficult for the student;

It is assumed that mathematics is the reason for students' absence from classes;

It is assumed that the teacher's manner of interpretation of the subject matter is crucially important for students;

It is assumed that students' attitude towards students' books varies;

It is assumed that the majority of students doubt their own knowledge in math and have no unique attitude regarding the way in which mathematics can help them in everyday life;

It is assumed that a small number of students positively rate mathematics classes, and the majority do not accept them.

In the process of sample choosing, adequate procedures were implemented, which enable that the sample is of appropriate size, homogeneity and is representative. Population in this research consisted of $8^{\text {th }}$ grade students from one school in
Živinice municipality and two schools in Tuzla municipality. These are: Elementary school Dubrave, Elementary school Solina and Elementary school Slavinovići. This research is very current according to temporal directionality. It is directed toward problems which follow mathematics teaching in elementary schools, which results in poor achievements of students in this school subject. This research is empirical for the most part. We began with concrete experience in educational process that is being examined, and based on data acquired, a conclusion was reached regarding its quality and value. While researching mathematics teaching process and relations and attitudes of students towards mathematics, analytical-descriptive method was used, method of theory analysis, causal analysis, survey method and method of observing pedagogic documentation. Adequate combination of these methods guarantees quality examination of the problem.

Analytical-descriptive method and theory analysis method showed the most important theoretical explorations and appearance of pedagogic-educational consequences. Considering the fact that the problem researched is very complex, it had to be explored analytically, and theoretically evaluate based on gathered data. Survey method was used in the stage of registering the presence of pedagogic-educational consequences in students, while registering the influence of negative consequences on students' achievements (Hadžić-Suljkić, 2009). In order to gather necessary concrete data relevant for this research, we used the following research techniques: questionnaire, scaling, analysis of pedagogic documentation, as well as compiling and statistically analyzing the gathered data. In this research, the starting point is that the relation towards a school subject significantly depends on students' capabilities and interests. However, the problem issue is also in what measure is the students' interest or motivation for learning a particular school subject, in this case mathematics, connected to teaching methods and work techniques in class, students' attitude toward the teacher, the students' book and curriculum, and understanding why this school subject will be significant in their lives and how they will use it. 
In this paper, data gathered through a questionnaire about elementary school students' attitudes towards mathematics classes has been analyzed. Results acquired served as basis for search for an answer to the set aim and tasks of this research. In other words, statistical procedures served to verify the set assumptions. Findings of the research showed how students see mathematics classes, which contributes to the advancement of students' relation towards classes and creating more amiable conditions for quality work. For the needs of this project, a research was conducted in Tuzla Canton schools, and data was gathered via survey about students' opinions regarding math classes, and then analyzed, statistically manipulated and interpreted in written and graphic form. Questionnaire, as an observational research method, served in order to collect more significant data, opinions, attitudes and beliefs of the examinees regarding their relation towards mathematics classes. Conclusions were formed based on students' responses. Survey was conducted during academic year 2011/12 in abovementioned schools.

\section{ANALYSIS AND INTERPRETATION OF RESEARCH RESULTS}

Student questionnaire (SQ) comprises of six clusters of questions. One hundred students gave answers to all questions. The first question cluster examines students' relation toward school subject mathematics. With this cluster, we wished to determine whether students possess certain affinities toward the given school subject, that is, how much they like or dislike the school subject mathematics. To the first question "I like mathematics and it is very interesting", over $50 \%$ of students answered that they find math partially interesting, and almost a third replied that it is not interesting at all (Graph 1). To the second question "Math is boring" students replied as follows (Graph 2).
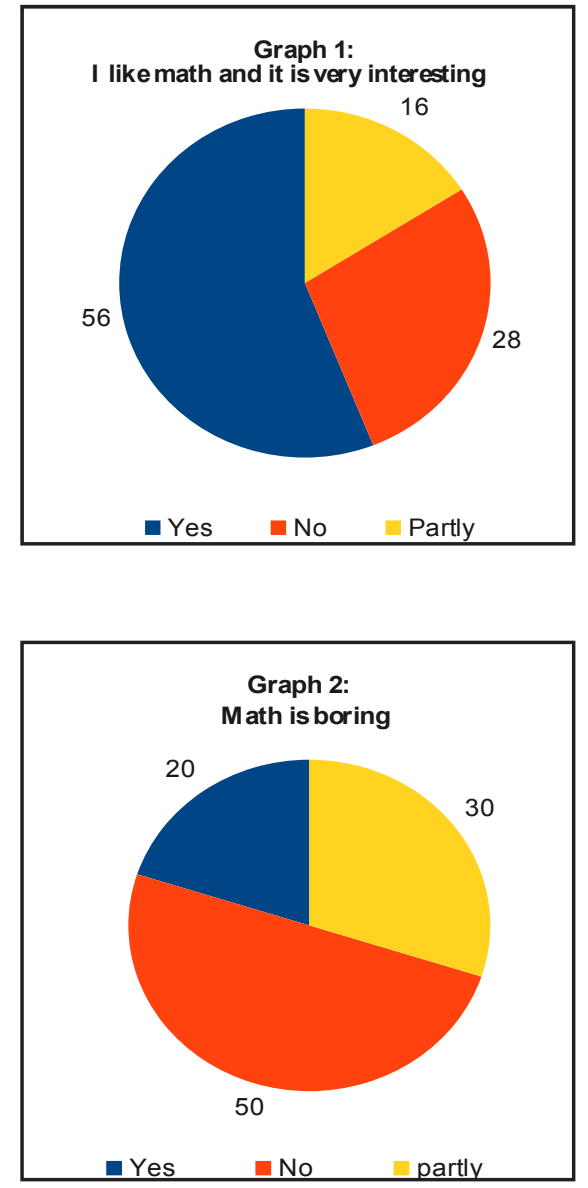

To the third question which examines relation between the student and school subject mathematics: "I would like to have more math classes at school", as many as 78 examinees replied NO, and only 6 students would like to have more math classes (Graph 3). To the fourth question "Math is often the reason why I skip classes", 90 of them replied NO. Such a high percentage can be explained by the fact that these are elementary school students, where absence from certain classes is very rare in relation to high school education (Graph 4).

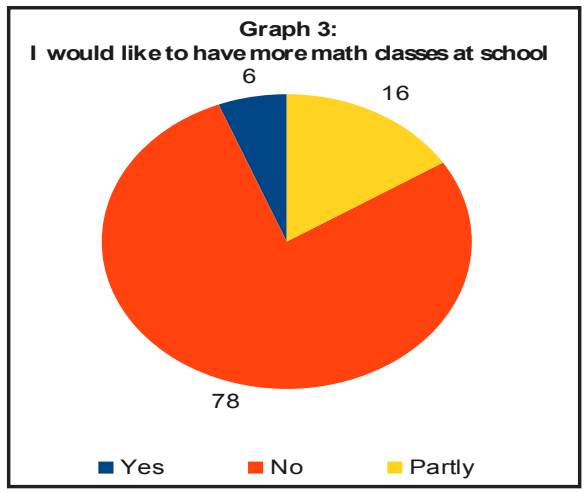




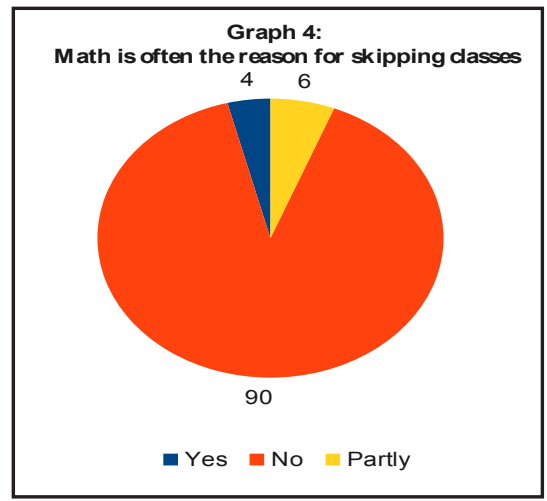

To the fifth posed question which examines the relation of students towards school subject mathematics "Subject matter is too voluminous", over half of the students replied YES or PARTLY, and answers were similar to the question "Subject matter is too difficult" (Graphs 5 and 6).
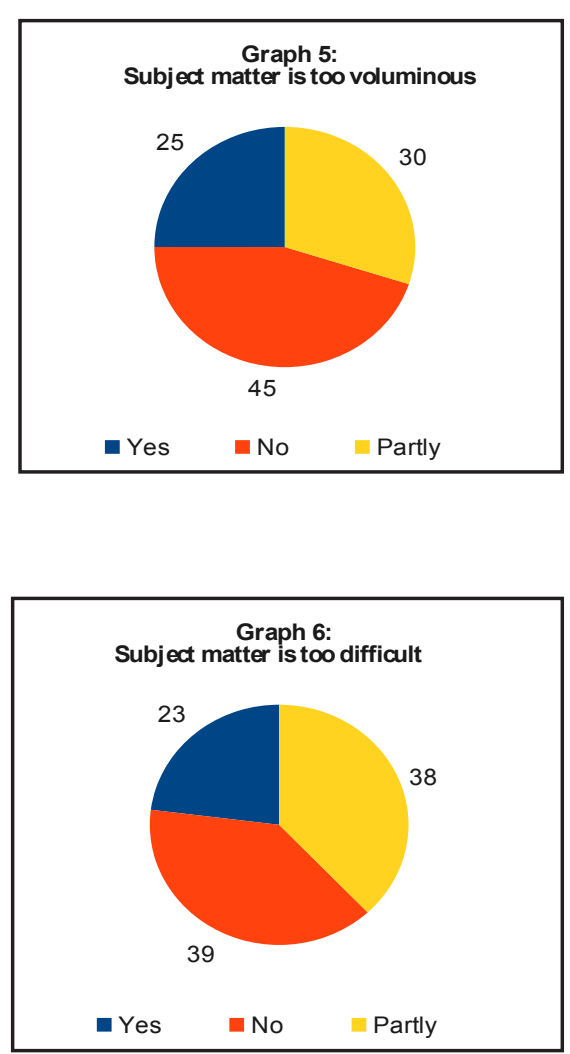

Analysis of replies to the question "My math studying at home is doing my homework" confirms that students pay very little attention to other manners of grasping the mathematics subject matter (Graph 7).

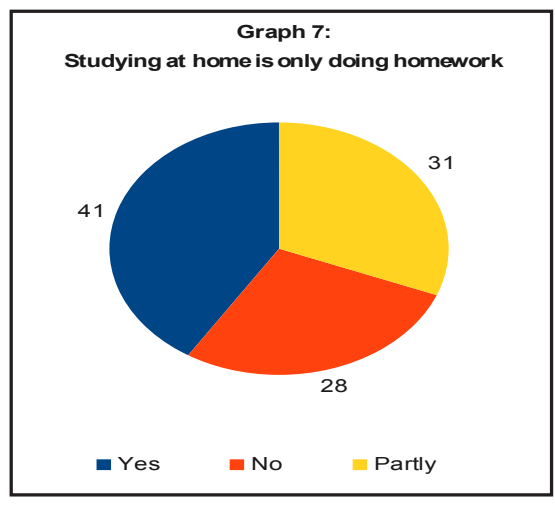

Another group of questions regards the process of determining in which elementary school grade the students find it easier, or more difficult, to master the subject matter. The analysis has confirmed that students in the 8th grade find the subject matter the most acceptable, and 7 th grade subject matter the most difficult (Graphs 8 and 9).
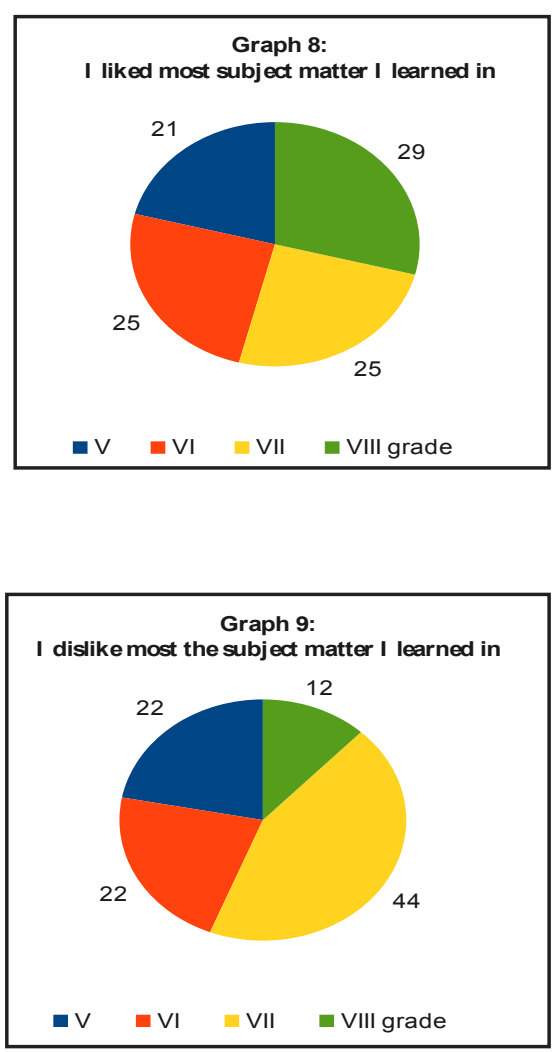

The third cluster of questions encompasses the relation students have towards mathematics teacher. Namely, it is well known that professional competence and responsibility of the teacher greatly 
contribute to the level of students' liking or disliking the school subject and how willing they will be to study it. To the questions "Teacher's manner of interpreting the subject matter is understandable, interesting and motivating" and "The teacher will gladly repeat interpretation and explain every ambiguity" students positively, that is, over $50 \%$ of them, replied YES (Graphs 10 and 11).
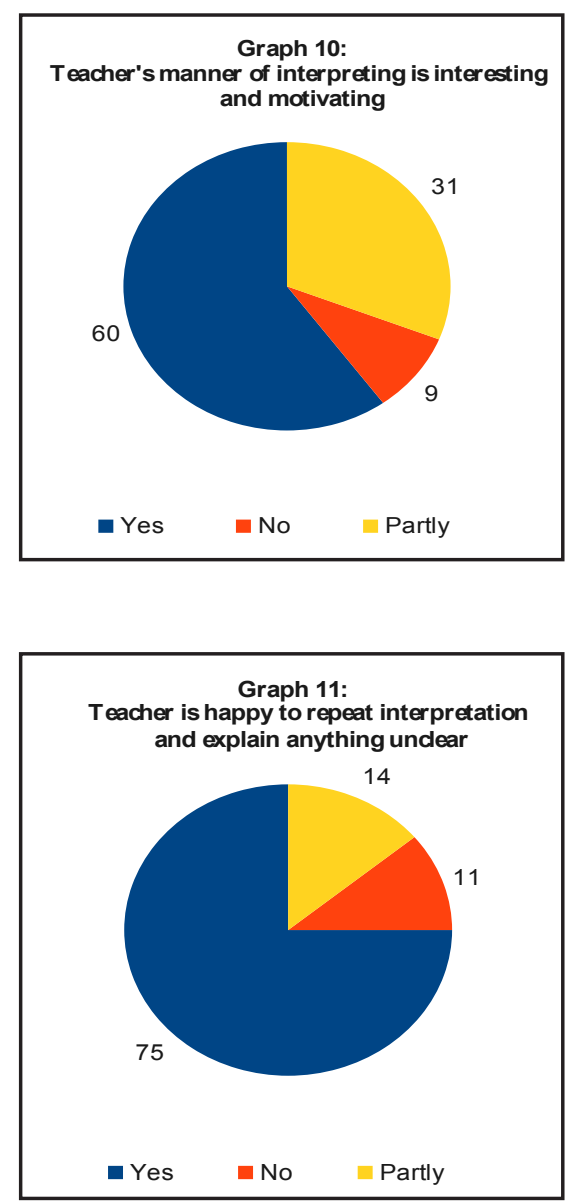

Answers to questions "Teacher him/herself teaches the new subject matter and we listen" and "When we learn new subject matter the teacher includes us" tell us that mathematics classes are mostly conducted frontally and lack interaction (Graphs 12 and 13).
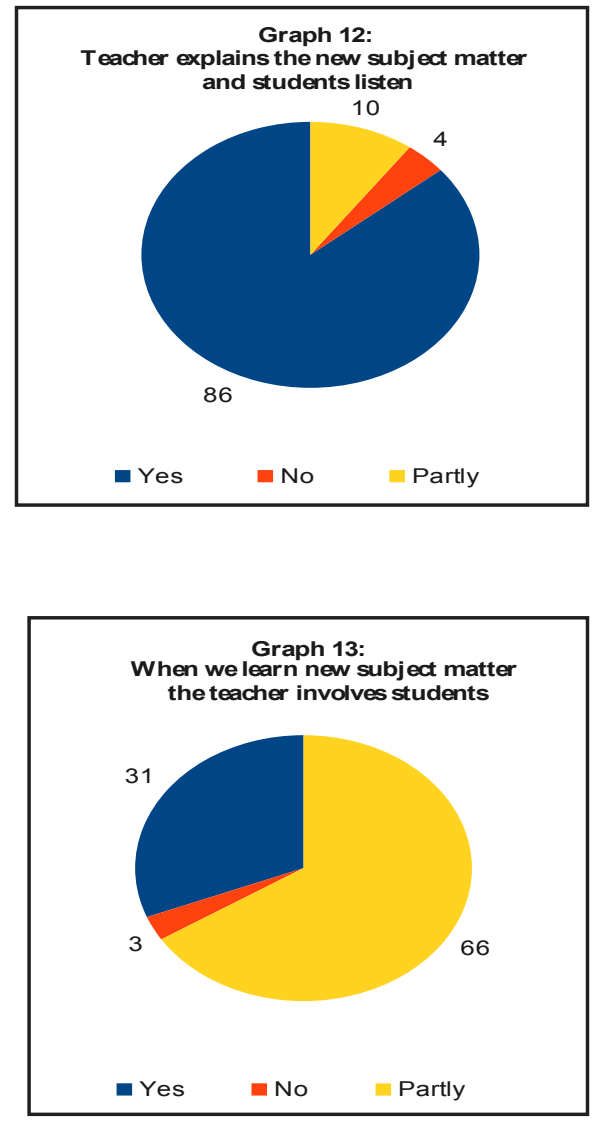

The fourth cluster of questions regards the opinion students have about the students' book, i.e. how much the books contribute to learning. To the first question from this cluster "Subject matter in the students' book is very understandable", as many as 79 students replied NO or partly, which is a poor result in a survey when it comes to mathematics students' books (Graph 14). Still, somewhat satisfactory are the answers to questions related to other knowledge sources in math (exercise books etc.) (Graphs 15, 16 and 17).

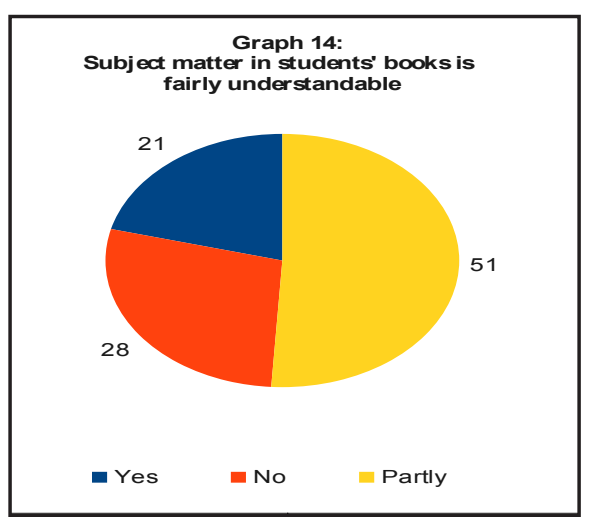



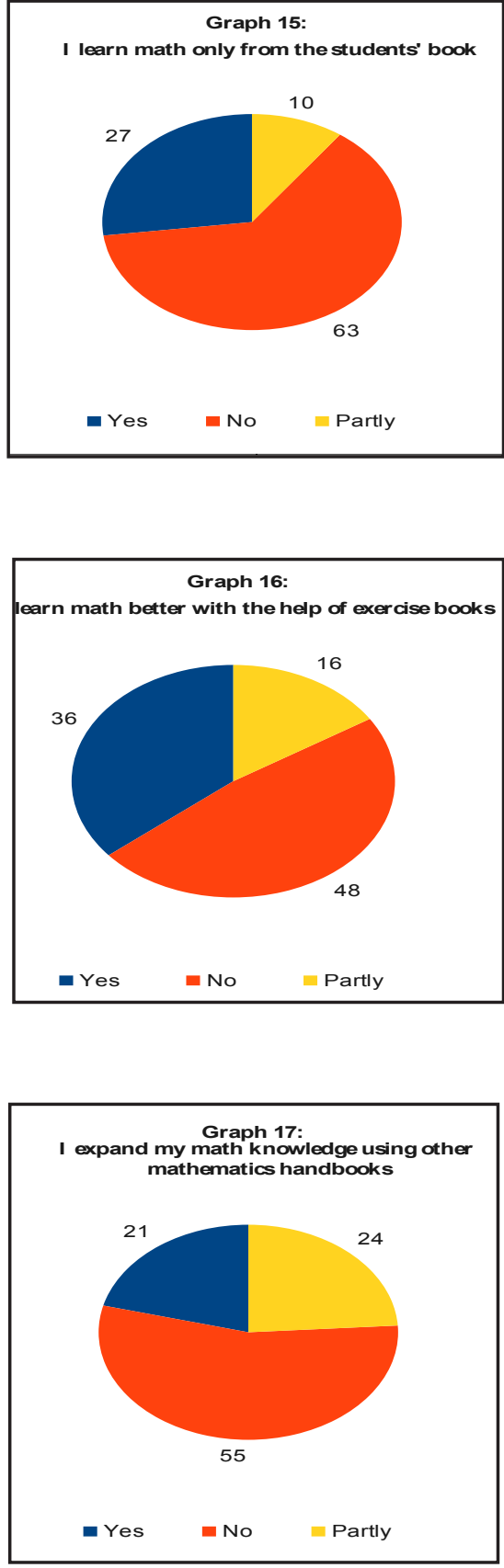

The fifth cluster of questions directly demands that students give their opinion, that is, to describe the significance of applicability of mathematical knowledge and its role in professional development and studying through life. Answers to the set questions clearly show that students are aware of the significance of math in further education and everyday life (Graphs 18, 19 and 20).
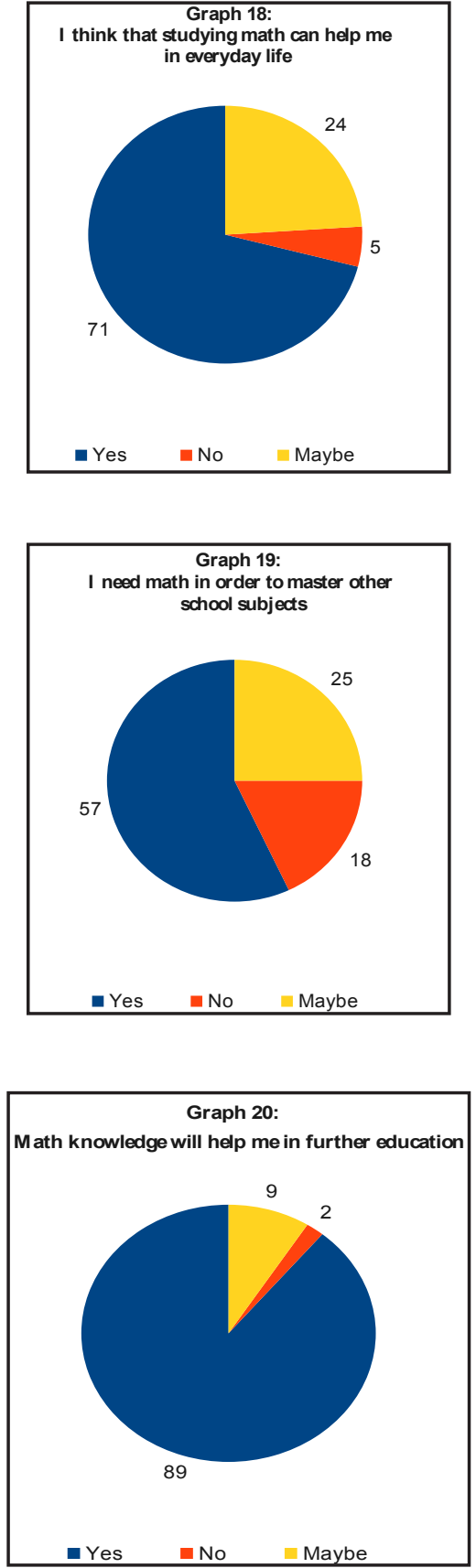

The sixth cluster of questions exhibits the students' attitude towards the teacher's manner of marking and evaluating students' knowledge. As we have already mentioned in this paper, the original assumption was that the teacher greatly influences students' relation towards mathematics as a subject. This cluster of five questions was intended to determine what is the attitude of students towards mathematics teacher's manner of marking and to what extent the teacher's marks contribute to students' attitude towards mathematics. 
To the first question "The teachers marks in a fair manner, the mark depends on the student's work and knowledge", most students, 73 of them, replied positively (YES) (Graph 21). the second question targeted to determine whether teachers' criteria during marking students are too soft and if it is too easy to get a good mark. Examinees' opinions say that the claim NO has the highest number of replies, which confirms that teachers do not have low criteria and that it is not too easy to get a good mark (Graph 22).
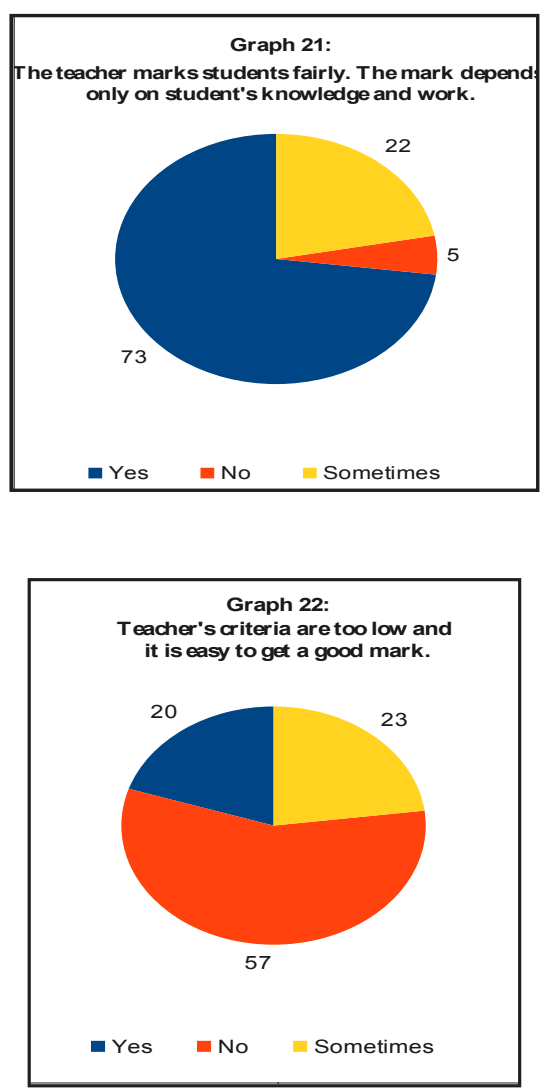

The aim of the following question was to determine whether the teacher sometimes gives away a mark in order to encourage a weak student. Results of the analysis shown in Graph 23 tell us that all three offered replies are evenly distributed in students' opinions. The next question was "Teacher marks both written and oral work of students" and the claim YES has the most replies.
This is confirmed by the fact that teacher marks both written and oral work of students (Graph 24).

The fifth question was aimed to ascertain if the teacher explains every mark he/she gives to a student. Examinees' replies mostly claimed YES and lead us to conclude that the teacher mostly elaborates on every mark he/she gives (Graph 25). If we look back at all five questions asked in terms of this task, we can notice that students have a positive attitude towards the teachers' manner of marking.
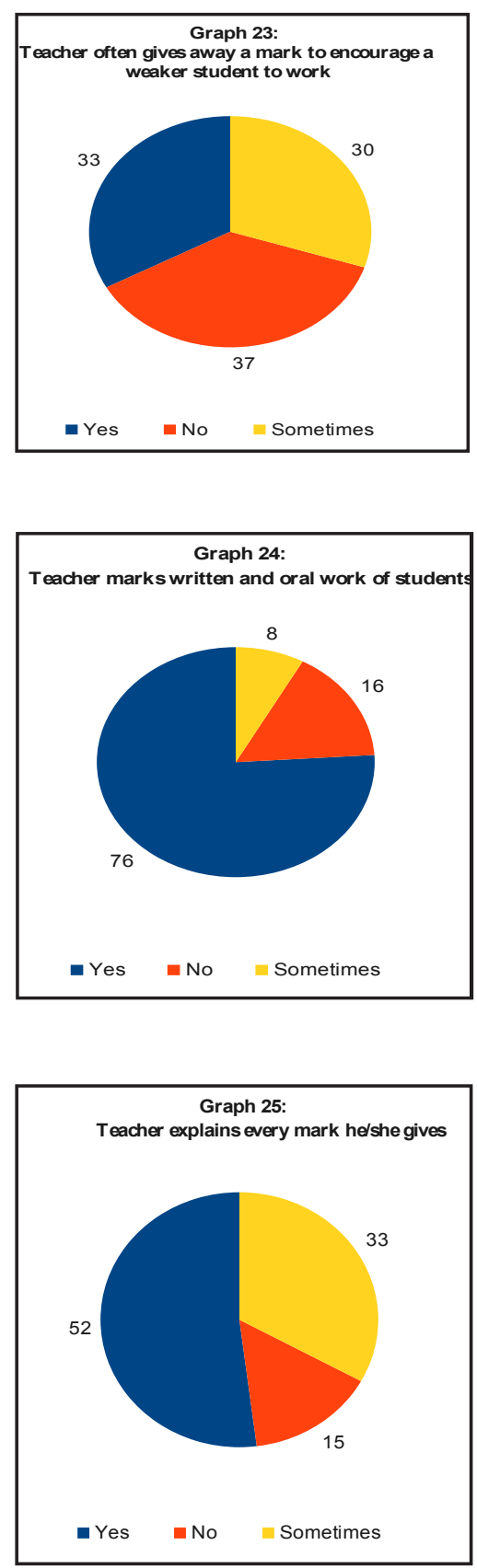


\section{CONCLUSION}

Mathematics as a science began developing several thousands of years ago, due to various needs, such as trading, measuring land surface, following astronomy events etc. Today, mathematics has a wide application. However, there is a widespread theory that mathematics is a bugbear for many students and that they escape even from the thought about math. Students, actually, do not know how to study mathematics, and therefore they do not understand it, find it boring and have low marks in this school subject. For society, the greatest problem is that many children with outstanding abilities tend to avoid high schools and universities where mathematics is present in curricula. It is well known that mathematics is the queen of sciences via its purity and elegance. Besides, in the world, it acquires on a daily basis greater direct and indirect influence, on other sciences as well as economy. Starting from the noticed and indicated problem, the aim of this paper was to research, critically analyze, determine and interpret the students' relation towards mathematics classes and the difficulties they encounter while mastering the subject matter, as well as, the level of interest and willingness to learn areas of mathematics curriculum. We emphasize only the most important elements here.

Based on theoretical research, applied methodology, and analysis and interpretation of gathered results, we arrived at a conclusion that students indeed don not find mathematics interesting enough, that is, the majority of students consider it boring and do not want to learn it in a greater volume in classes. Students are dissatisfied with 7 th grade curriculum, and like the 8 th grade curriculum the most. They have also given low marks regarding the quality of mathematics students' books. Still, their attitude is almost unique when it comes to their belief that mathematics can greatly help them in studying through life.

\section{REFERENCES}

Hadžić-Suljkić, M. (2009). Metodologija istraživanja u odgoju i obrazovanju [Research Methodology in Education]. B\&H, Tuzla: PrintCom.

Posokhova, I. (2009). about the book Mahesh C. S.: Matematika bez suza, Kako pomoći djetetu s poteškoćama u učenju matematike [Mathematics without tears, how to help children with difficulties in learning mathematics].

Legović, T. (2004). Tri koraka prema unapređenju nastave matematike [Three steps towards improving the teaching process of mathematics]. Osječka matematička škola, 4 (1), 1925. 